\title{
Original Article \\ Cervical lymph node metastases of squamous cell carcinoma from an unknown primary: Outcomes and patterns of failure
}

\author{
Mistry RC, Qureshi SS, Talole SD1, Deshmukh S \\ Departments of Head and Neck Services, 'Biostatistics, Tata Memorial Hospital, Ernest Borges Road, \\ Parel, Mumbai, India.
}

Correspondence to: Dr Rajesh Mistry, E-mail: musica@vsnl.com

\begin{abstract}
CONTEXT: Management of cervical lymph nodes metastases of squamous cell carcinoma (SCC) from primary of unknown origin (PUO) is contentious and there is insignificant data from India on this subject. AIMS: To present experience of management of these patients treated with curative intent at a single institution. SETTINGS AND DESIGN: Retrospective study of patients treated between 1989-1994 in a tertiary referral cancer centre. MATERIALS AND METHODS: Eighty-nine patients were evaluated in the study period and their survival compared with patients with common sites of primary in the head and neck with comparable node stage. STATISTICAL ANALYSIS USED: Kaplan-Meier method. RESULTS: The clinical stage of the neck nodes at presentation was N1 in 11\%, N2a in $28.5 \%, \mathrm{~N} 2 \mathrm{~b}$ in $22.5 \%$, N3 in $35 \%$ and Nx in $3.4 \%$ patients. All patients underwent surgery and 70 patients received more than $40 \mathrm{~Gy}$ postoperative radiotherapy. Twentynine $(32.6 \%)$ patients had relapse of which $19(21 \%)$ were in the neck. Postoperative radiotherapy did not influence the neck relapse $(p=0.72)$. Primary was detected in 13 patients (14.6\%) on subsequent follow up. The overall five and eightyears survival was $55 \%$ and $51 \%$ respectively. The overall five-year survival was better compared to patients with known primary with comparable node stage. CONCLUSIONS: Patients with cervical lymph nodes metastases of SCC from PUO have reasonable survival and low rate of development of subsequent primary when treated with surgery and radiotherapy. The overall survival is comparable to that of patients with known primary and hence an attempt at cure should always be made.
\end{abstract}

Key words: Cervical metastases, head and neck, squamous cell carcinoma, unknown primary.

\section{Introduction}

M etastases of squamous cell carcinoma (SCC) to cervical lymph nodes from primary of unknown origin (PU O) represent $1 \%$ to $2 \%$ of head and neck cancers. ${ }^{[1-3]}$ The explanations for this unusual form of presentation are of speculative nature: spontaneous regression of the primary and inability to detect a small primary particularly in the nasopharynx, which is known to metastasize to nodes at an early stage. U nlike metastatic lymph nodes from PU O at other body sites, the prognosis in metastatic cervical nodes is not discouraging. The fiveyear overall survival rates range between $40 \%$ to $60 \%$ in recent series. ${ }^{[3-7]} \mathrm{H}$ owever, the optimal management of these patients remains controversial. The lack of randomized studies comparing treatment options has led to therapeutic decision based on retrospective non- randomized studies involving patients managed with various diagnostic and therapeutic procedures and institutional policies. ${ }^{[2,4,5,8,9]}$ Although sufficient data exist in the literature on the subject, reports from India are deficient. ${ }^{[10]}$

The paper presents the experience at the Tata M emorial $\mathrm{H}$ ospital with treatment of patients with SCC metastatic to cervical lymph nodes from PU 0 .

\section{Materials and Methods}

The study included 89 patients with metastases of SCC to cervical lymph nodes from PU 0 treated with curative intent between 1989 to 1994. The study excluded patients who received palliative therapy because of advanced or comorbid disease, with histology other than 
SCC and distant metastases at the time of diagnosis.

The median age of patients was 55 years (range 28 to 84 years). There were 78 men and 11 women. Forty-six patients had involvement of right sided cervical nodes and 43 had left sided nodes. The frequency of metastatic lymph nodes at various neck levels were as follows: level 1, 9 patients ( $10 \%)$; level 2, 67 patients $(75 \%)$; level 3, 46 patients $(51.7 \%)$; level 4,12 patients ( $13.5 \%)$; level 5, 1 patient (1\%). All patients were staged according to the 2002 A merican Joint Committee on Cancer (AJCC) system for nodal disease in the head and neck region. ${ }^{[11]}$ The clinical stage of the neck at presentation was N 1 in 10 patients ( $11 \%), \mathrm{N} 2 \mathrm{a}$ in 25 patients $(28.5 \%), \mathrm{N} 2 \mathrm{~b}$ in 20 patients $(22.5 \%), \mathrm{N} 3$ in 31 patients $(35 \%)$ and $\mathrm{Nx}$ in 3 patients (3.4\%). The diagnosis of SCC in neck nodes was confirmed by FNAC in 50 patients (56\%) and by open biopsy performed elsewhere in 39 patients (44\%).

The provisional diagnosis of neck node metastases with unknown primary was made after a comprehensive clinical examination of the upper aerodigestive tract failed to detect a primary lesion. All patients underwent chest X-ray, barium swallow, X-ray of the nasopharynx and paranasal sinuses. Computerized Tomography (CT) was performed as a routine in the later years of the study. Subsequently patients underwent a meticulous examination under anesthesia with panendoscopy (direct laryngoscopy, oesophagoscopy, nasopharyngoscopy and bronchoscopy) and palpation of nasopharynx and base of tongue. Random biopsies and washings for cytology from tonsil, base of tongue and/or nasopharynx was not performed. If these investigations failed to reveal the primary tumor, diagnosis of cervical node metastases from PU 0 was established.

All patients underwent neck dissection and were advised postoperative RT. Ten patients did not take RT and nine patients did not complete RT for various reasons. Thus 19 patients (21\%) had none or less than $40 \mathrm{~Gy}$ and the remaining 70 patients (79\%) had $40 \mathrm{~Gy}$ or more of postoperative RT. The RT portals were unilateral, bilateral or antero-posterior depending on the discretion of the treating radiotherapist.

Patients were followed-up at regular interval; endoscopy and/or imaging were performed if patient was symptomatic or clinical examination raised suspicion of primary. Follow-up were completed by letters, telephone calls and home visits.

The survival was measured from the date of diagnosis to the last day of follow-up or to death. The data was analyzed using SPSS for windows version 11.5 statistical software. Survival was computed by the Kaplan-M eier method and compared by log-rank testing.

\section{Results}

In six (7\%) patients none of the nodes were metastatic; all of them had open biopsy before neck dissection. In six $(7 \%)$ patients nodes were involved at a single level and in seven (8\%) patients, nodes were involved at all levels in the neck [Table 1]. Details of the level at which nodes where involved is listed in Table 2. Extra nodal disease was reported in $59(66 \%)$ patients.

Fifty-one patients were alive at the time of review. Ten patients died due to recurrent disease, ten died of subsequent primary, nine patients died of distant metastases, one patient had recurrent disease and distant metastases and in eight patients the cause of death was not known.

The five and eight-year overall survival for all patients was $55 \%$ and $51 \%$ respectively, with median survival of 98 months [Figure 1]. Patient with N 1 neck stage at presentation showed a trend towards better survival as compared to $\mathrm{N} 2$ and $\mathrm{N} 3$ together at 30 months [Figure 2], although this was not statistically significant $(P=0.16)$. Similarly extra nodal spread also showed a weak evidence of having an impact on survival $(P=0.07)$. $\mathrm{H}$ owever, postoperative radiotherapy, prior open biopsy of the node and involvement of nodes at multiple levels in the neck did not have any impact on the survival.

\begin{tabular}{lc}
\hline $\begin{array}{l}\text { Table 1: Number of histologically involved nodal } \\
\text { levels }\end{array}$ & Number of patients (\%) \\
\hline Number of Levels & $6(7)$ \\
\hline None & $6(7)$ \\
\hline 1 & $15(17)$ \\
\hline 2 & $42(47)$ \\
\hline 3 & $13(15)$ \\
\hline 4 & $7(8)$ \\
\hline
\end{tabular}

Table 2: Topographic distribution of metastatic lymph nodes

\begin{tabular}{lcc}
\hline Level & Clinical (\%) & Pathological (\%) \\
\hline I & $9(10)$ & $21(23.6)$ \\
\hline II & $67(75)$ & $76(85.4)$ \\
\hline III & $46(51.7)$ & $74(83)$ \\
\hline V & $12(13.5)$ & $59(66.3)$ \\
\hline
\end{tabular}




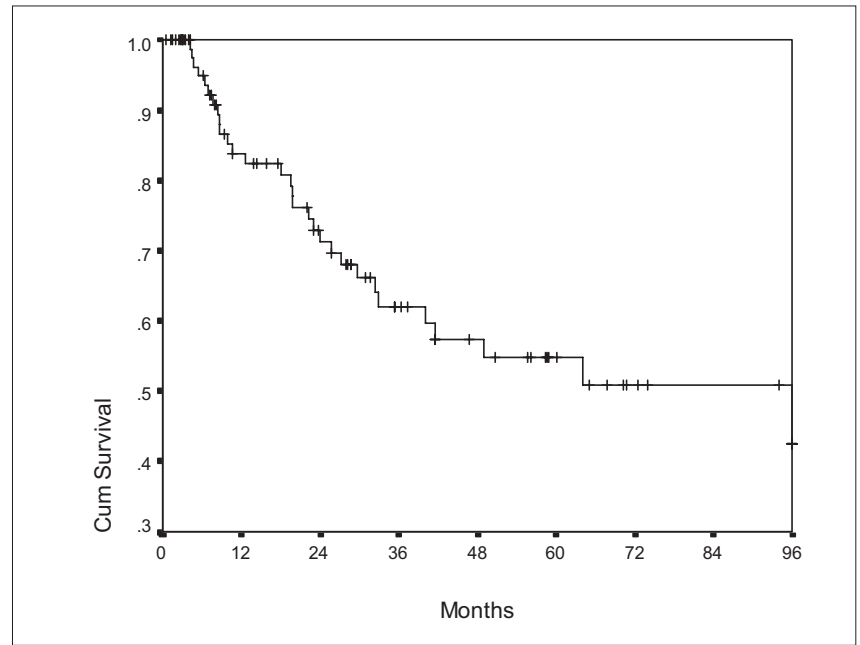

Figure 1: Overall survival of 89 patients

Twenty-nine patients (32.6\%) had relapse of disease. The site of relapse was neck in 19 patients $(21.3 \%)$, distant in nine (10\%) patients and neck with distant failure in one patient. Four of the 19 patients (21\%) who received less than $40 \mathrm{~Gy}$ postoperative RT and 15 of 60 (25\%) patients who received more than $40 \mathrm{~Gy}$ of post-operative RT developed a neck relapse $(P=0.72)$. O nly three of the 29 patient with relapse of disease were alive.

The primary was detected in 13 patients (14.6\%) on follow-up. Two of these patients received less than 40 $\mathrm{Gy}$ and 11 had more than $40 \mathrm{~Gy}$ of RT. The mean time to detection of the primary was 24 months. In two patients, the primary was detected in less than a year and could represent missed primaries. The commonest site of the primary was oropharynx; none presented with primary in nasopharynx [Table 3]. All, except three with primary in hypopharynx, Iarynx and oral cavity, died of disease.

The survival of patients with known primary site treated in Tata Memorial Hospital is reported in the Hospital Registry. ${ }^{[12]}$ The five-year survival of patients with common sites of primary in the head and neck area was compared with the patients reported in this study. For comparable node stage the overall survival was better for patients with unknown primary [Table 4].

\section{Discussion}

The diagnosis of cervical node metastases from PU 0 is made after thorough assessment fails to reveal the presence of tumor in the upper aerodigestive tract. In addition to the array of investigations, many reports have advocated tonsillectomy, blind biopsies and/or washings for cytology from nasopharynx, and base tongue. ${ }^{[1,13-15]} \mathrm{H}$ owever, none of the patients reported

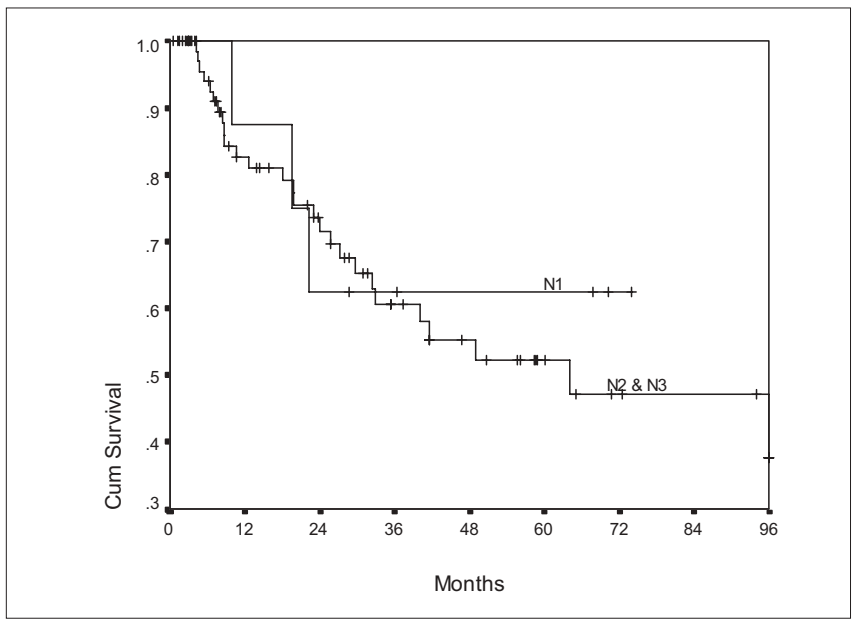

Figure 2: Overall survival according to node stage at presentation

in this study underwent routine blind biopsies and yet the rate of detection of primary on subsequent followup was no higher than reported in the literature, thus questioning the role of these investigations in the work up for PU O. Similar conclusion can be drawn for CT scan. In gastrointestinal cancers CT is considered to be less sensitive in identifying small peritoneal deposits and superficial liver metastases. $\mathrm{H}$ ence the importance of laparoscopy, wherein there is direct visualization of the abdominal cavity is substantial. ${ }^{[16]}$ A kin to this in cervical metastases from PU O, the primary, if there is one, is likely to be small the best investigation would

Table 3: Location of the primary $(n=13)$

\begin{tabular}{lc}
\hline Site of primary & Number of patients \\
\hline Nasopharynx & Nil \\
\hline Oropharynx & 6 \\
\hline Pyriform sinus & 2 \\
\hline Larynx & 2 \\
\hline Lung & 2 \\
\hline Oral cavity & 1
\end{tabular}

Table 4: Comparison of five-year survival of patients with known and unknown primary*

\begin{tabular}{lcccc}
\hline Site of primary & N0 & N1 & N2 & N3 \\
\hline Tonsil & 21 & 14 & - & 5.5 \\
\hline Oropharynx & 24 & 4 & 14 & 6 \\
\hline Pyriform sinus & 30 & 17 & 8 & 4 \\
\hline Nasopharynx & 25 & 21 & 29 & 19 \\
\hline Unknown & - & 63 & 63 & 32 \\
\hline $\begin{array}{l}{ }^{*} \text { Comparison based on survival of patients with known primary reported in } \\
\text { the Hospital Registry. }{ }^{[12],} \text { Figures are in percentage }\end{array}$
\end{tabular}

Indian Journal of Cancer | April-June 2008 | Volume 45 | Issue 2 
be thorough examination of all the mucosal areas in the upper aerodigestive tract rather than relying on CT scan which is not ideal for detecting small lesions.

Hence we believe that imaging of the neck, if performed, should be to define the extent of nodal disease and its resectability rather than search for a primary. H owever, Sinnathamby et al and other authors recommend routine imaging so as to avoid missing an occult primary and unnecessary radiation to mucosal areas. ${ }^{[2]}$ Lately newly introduced diagnostic methods have also been endeavored. Fluorodeoxyglucose (FDG) positron emission tomography (PET) or single-photonemission computed tomography (SPECT) have been utilized. H owever, limited data has suggested that they are useful only in small subsets of patients. ${ }^{[1,14,15,17]}$ L aser-induced fluorescence imaging, Epstein-Barr virus (EBV) evaluation in metastatic lymph nodes by in situ hybridization, $\mathrm{H}$ uman papilloma virus (H PV) detection by polymerase chain reaction, microsatellite mutation analysis of metastatic nodal tissue and samples of normal pharyngeal mucosa were also proposed. ${ }^{[18-21]}$

The management of patients with cervical metastases from PU O evokes considerable controversy and has not been standardized. $\mathrm{N}$ ieder et $\mathrm{al}_{1}{ }^{[1]}$ in their review have suggested surgery alone in selected patients with $\mathrm{N} 1$ disease without extracapsular extension and with no history of incisional or excisional biopsy based on their finding of an appearance rate of the primary tumor of $25 \%$, median nodal recurrence rate of $34 \%$ and overall five-year survival rate of $66 \%$. The application of RT has ranged from RT alone to postoperative RT and the portals included spanned from ipsilateral neck nodes to bilateral neck nodes and the putative primary sites. ${ }^{[2-7,22]}$ There is evidence that patients receiving postoperative RT to bilateral neck nodes and potential primary sites have higher reported control odds and survival rate than patients receiving postoperative ipsilateral RT or RT alone ${ }^{[5]} \mathrm{N}$ evertheless, considering the lack of comparative studies, the optimal radiotherapy strategy remains to be delineated. Similarly, the role of chemotherapy in the management of PUO with cervical metastases is also indistinct. In fact, in the review by $\mathrm{N}$ ieder et $\mathrm{al}^{,{ }^{11]}}$ substantial data supporting the use of chemotherapy was deficient.

The incidence of subsequent primary in our series (15\%) is in agreement with incidence reported by other studies where postoperative RT was routinely administered. $[1,4-7,22]$ We did not include any patient with metastases of undifferentiated carcinoma in the study. This could explain why none of the primary was found in the nasopharynx. As reported in the literature, patients in whom primary was detected later did poorly as compared to those who continued to be free of disease. ${ }^{[5,14]}$

Postoperative RT did not help in controlling the disease in the neck for $21 \%$ patients who had less than 40 Grays versus $25 \%$ in those who had 40 Grays or more of radiation $(P=0.72)$. This is contrary to the experience at the Memorial Sloan Kettering $\mathrm{H}$ ospital where postoperative radiation failed to influence the overall survival but helped in improving the local control. ${ }^{[23]}$ I ganej also described a similar experience with postoperative RT. ${ }^{[7]}$

$\mathrm{N}$ umerous factors have been recognized influencing the overall survival including node stage, number of histologically involved nodes, grading, presence of extra nodal disease and performance status. ${ }^{[1-4,24]}$ In our study presence of extra capsular disease had a minor impact on survival and nodal stage at presentation showed a trend towards better survival although it did not achieve statistical significance. $N$ one of the other factors studied (open node biopsy, presence of metastatic nodes at multiple levels, tumor grade and postoperative radiotherapy) had impact on the overall survival.

The five-year survival of $55 \%$ is comparable to published results. ${ }^{[3,5,6,23-25]}$ We compared the overall survival of these patients with that of patients with known primary at common sites in the head and neck region as reported in the hospital registry. ${ }^{[12]}$ For comparable node stage, patients with occult primary appear to fare better than patients with known primary [Table 5]. This observation should be interpreted with caution as the comparison is with historical data. Jones et al, on similar comparison did not find any difference in the survival between the two groups. ${ }^{[26]}$

The limitation of this study is its retrospective nature. However all the patients had similar histology and treatment was uniform in all patients. Based on this, it appears that routine blind biopsies from upper aerodigestive tract may not be necessary. $\mathrm{N}$ odal stage at presentation and extra capsular disease has a role in outcome of these patients.

In conclusion, the optimal diagnostic and therapeutic approach still eludes us. The first randomized trial proposed by the European O rganization for R esearch on Treatment of Cancer (EORTC), Radiation Therapy Oncology Group (RTOG), and other cooperative groups from Australia, Canada, Denmark and Germany (study 24001-22005) is ongoing. ${ }^{[1,14]}$ The results of this trial will help in expounding several questions regarding passable management of cervical metastases from PU 0 . 


\section{References}

1. Nieder C, Gregoire V, Ang KK. Cervical lymph node metastases from occult squamous cell carcinoma: Cut down a tree to get an apple? Int I Radiat Oncol Biol Phys 2001:50:727-33.

2. Sinnathamby K, Peters LJ, Laidlaw C, Hughes PG. The occult head and neck primary: To treat or not to treat? Clin Oncol (R Coll Radiol) 1997;9:322-9.

3. Grau C, Johansen LV, Jakobsen J, Geertsen P, Andersen E, Jensen BB. Cervical lymph node metastases from unknown primary tumours. Results from a national survey by the Danish Society for Head and Neck Oncology. Radiother Oncol 2000;55:121-9.

4. Colletier PJ, Garden AS, Morrison WH, Goepfert H, Geara F, Ang KK. Postoperative radiation for squamous cell carcinoma metastatic to cervical lymph nodes from an unknown primary site: Outcomes and patterns of failure. Head Neck 1998;20:674-81.

5. Reddy SP, Marks JE. Metastatic carcinoma in the cervical lymph nodes from an unknown primary site: Results of bilateral neck plus mucosal irradiation vs. ipsilateral neck irradiation. Int J Radiat Oncol Biol Phys 1997;37:797-802.

6. Erkal HS, Mendenhall WM, Amdur RJ, Villaret DB, Stringer SP. Squamous cell carcinomas metastatic to cervical lymph nodes from an unknown head-and-neck mucosal site treated with radiation therapy alone or in combination with neck dissection. Int J Radiat Oncol Biol Phys 2001;50:55-63

7. Iganej S, Kagan R, Anderson P, Rao A, Tome M, Wang R, et al. Metastatic squamous cell carcinoma of the neck from an unknown primary: Management options and patterns of relapse. Head Neck 2002;24:236-46.

8. Tong CC, Luk MY, Chow SM, Ngan KC, Lau WH. Cervical nodal metastases from occult primary: Undifferentiated carcinoma versus squamous cell carcinoma. Head Neck 2002;24:361-9.

9. McMahon J, Hruby G, O'Brien CJ, McNeil EB, Bagia JS, Clifford AR, et al. Neck dissection and ipsilateral radiotherapy in the management of cervical metastatic carcinoma from an unknown primary. Aust $\mathrm{N}$ Z J Surg 2000;70:263-8.

10. Shenoy AM, Hasan S, Nayak U, Anantha N, Reddy BK, Kannan V, et al. Neck metastasis from an occult primary-the Kidwai experience. Indian J Cancer 1992;29:203-9.

11. American Joint Committee on Cancer. In: Greene FL, Page DL, Fleming ID, Fritz AG, Balch CM, Haller DG, et al, editors. American Joint Committee on Cancer Staging Manual. Head and Neck sites. $6^{\text {th }}$ ed. New York: Springer-Verlag; 2002. p. 17-22.

12. Dinshaw KA, Rao DN, Shroff PD. Annual Report 1987, Hospital Cancer Registry. Mumbai: Tata Memorial Hospital; 1989.

13. Lapeyre M, Malissard L, Peiffert D, Hoffstetter S, Toussaint B, Renier S, et al. Cervical lymph node metastasis from an unknown primary: Is a tonsillectomy necessary? Int J Radiat Oncol Biol Phys 1997;39:291-6
14. Jereczek-Fossa BA, Jassem J, Orecchia R. Cervical lymph node metastases of squamous cell carcinoma from an unknown primary. Cancer Treat Rev 2004;30: 153-64.

15. Mendenhall WM, Mancuso AA, Amdur RJ, Stringer SP, Villaret DB, Cassisi NJ. Squamous cell carcinoma metastatic to the neck from an unknown head and neck primary site. Am J Otolaryngol 2001;22:261-7.

16. Weickert U, Jakobs R, Riemann JF. Diagnostic laparoscopy. Endoscopy 2005;37:33-7.

17. Greven KM, Keyes JW Jr, Williams DW $3^{\text {rd }}$, McGuirt WF, Joyce WT $3^{\text {rd }}$ Occult primary tumors of the head and neck: Lack of benefit from positron emission tomography imaging with 2-[F-18]fluoro-2-deoxyD-glucose. Cancer 1999;86:114-8.

18. Kulapaditharom B, Boonkitticharoen V, Kunachak S. Flourescenceguided biopsy in the diagnosis of an unknown primary in patients with metastatic cervical lymph nodes. Ann Otol Rhinol Laryngol 1999; 108:700-4.

19. Lee WY, Hsiao JR, Jin YT, Tsai ST. Epstein-Barr virus detection in neck metastases by in-situ hybridization in fine needle aspiration cytologic studies: An aid differentiating the primary site. Head Neck 2000;22:336-40

20. Gillison ML, Koch WM, Capone RB, Spafford M, Westra WH, Wu L, et al. Evidence for a causal association between human papillomavirus and a subset of head and neck cancers. J Natl Cancer Inst 2000;92:709-20.

21. Califano J, Westra WH, Koch W, Meininger G, Reed A, Yip L, et al. Unknown primary head and neck squamous cell carcinoma: molecular identification of the site of origin. J Natl Cancer Inst 1999:91:599-604.

22. Strojan P, Anicin A. Combined surgery and postoperative radiotherapy for cervical lymph node metastases from an unknown primary tumour. Radiother Oncol 1998;49:33-40.

23. Davidson BJ, Spiro RH, Patel S, Patel K, Shah JP. Cervical metastases of occult origin: The impact of combined modality therapy. Am J Surg 1994; 168:395-9.

24. Fernandez JA, Suarez C, Martinez JA, Llorente JL, Rodrigo JP, Alvarez JC. Metastatic squamous cell carcinoma in cervical lymph nodes from an unknown primary tumour: prognostic factors. Clin Otolaryngol Allied Sci 1998;23: 158-63.

25. Weir L, Keane T, Cummings B, Goodman P, O'Sullivan B, Payne D, et al. Radiation treatment of cervical lymph node metastases from an unknown primary: An analysis of outcome by treatment volume and other prognostic factors. Radiother Oncol 1995;35:206-11.

26. Jones AS, Cook JA, Phillips DE, Roland NR. Squamous carcinoma presenting as an enlarged cervical lymph node. Cancer 1993;27:1756-61.

Source of Support: Nil, Conflict of Interest: None declared. 